\title{
Removal of Methylene Blue from Aqueous Solution by Activated Carbon Prepared from Pea Shells (Pisum sativum)
}

\author{
Ünal Geçgel, Gülce Özcan, and Gizem Çağla Gürpınar \\ Arda Vocational College, Trakya University, 22030 Edirne, Turkey \\ Correspondence should be addressed to Ünal Geçgel; unalgecgel@trakya.edu.tr
}

Received 4 June 2012; Revised 14 August 2012; Accepted 22 August 2012

Academic Editor: Kaustubha Mohanty

Copyright (C) 2013 Ünal Geçgel et al. This is an open access article distributed under the Creative Commons Attribution License, which permits unrestricted use, distribution, and reproduction in any medium, provided the original work is properly cited.

\begin{abstract}
An activated carbon was prepared from pea shells and used for the removal of methylene blue (MB) from aqueous solutions. The influence of various factors such as adsorbent concentration, initial dye concentration, temperature, contact time, $\mathrm{pH}$, and surfactant was studied. The experimental data were analyzed by the Langmuir and Freundlich models of adsorption. The adsorption isotherm was found to follow the Langmuir model. The monolayer sorption capacity of activated carbon prepared from pea shell for $\mathrm{MB}$ was found to be $246.91 \mathrm{mg} \mathrm{g}^{-1}$ at $25^{\circ} \mathrm{C}$. Two simplified kinetic models including pseudo-first-order and pseudo-second-order equation were selected to follow the adsorption processes. Kinetic studies showed that the adsorption followed pseudo-secondorder kinetic model. Various thermodynamic parameters such as $\Delta H^{\circ}, \Delta S^{\circ}$, and $\Delta G^{\circ}$ were evaluated. The results in this study indicated that activated carbon prepared from pea shell could be employed as an adsorbent for the removal of MB from aqueous solutions.
\end{abstract}

\section{Introduction}

Wastewater from textiles, cosmetics, printing, dying, food processing, and paper-making industries is polluted by dyes. Discharge of these colored effluents presents a major environmental problem for developing countries because of their toxic and carcinogenic effects on living beings [1]. Therefore many methods such as activated carbon sorption, chemical coagulation, ion exchange, electrolysis, and biological treatments $[2,3]$, have been developed for removing dye pollutions from wastewater before being discharged into the environment. Of these methods, activated carbon sorption is highly effective for the removal of dyes and pigments as well as other organic and inorganic pollution [4-10].

There are two basic processes to activate carbon materials, physical and chemical. The temperatures used in chemical activation are lower than that used in the physical activation process. As a result the development of a porous structure is better in the case of chemical activation method. Chemical activation can be accomplished in a single step by carrying out thermal decomposition of raw material with chemical reagents. Chemical activation processes have been carried out with acidic reagents, that is, $\mathrm{ZnCl}_{2}$ [11], $\mathrm{H}_{3} \mathrm{PO}_{4}$ [12], $\mathrm{HCl}$ [13], and $\mathrm{H}_{2} \mathrm{SO}_{4}$ [14] or with basic reagents $\mathrm{KOH}$ [14], $\mathrm{K}_{2} \mathrm{CO}_{3}$ [15], $\mathrm{NaOH}$ [12], and $\mathrm{Na}_{2} \mathrm{CO}_{3}$ [16].

This leads to searches for new, cheap, and easily available resources of carbon as a feedstock for activated carbon. Many cheap, easily available agricultural and/or plant-based materials such as silk cotton hull, coconut tree sawdust, sago industry waste, banana pith, maize cob [17], rattan sawdust [18], jute fiber [19], pistachio shells [20], palm kernel shell [21], date pits [22], rice bran [23], coir pith [24], rice husk [12], mango seed kernel powder [25], rubberwood sawdust [26], plum kernels [27], rosewood sawdust [28], straw [29], coconut coir dust [30], palm fibre [31], pine cone [32], walnut shell, almond shell, hazelnut shell, apricot stones [33], coconut shells, groundnut shell, bamboo dust [34], deolied soya [35], and wheat husk [36] have been used as a source of the production of activated carbon for the removal of textile dye effluents.

However there are no reports of obtaining active carbon from pea shells by chemical and physical activation methods [37]. Therefore, in this paper, the adsorption equilibrium 
and kinetics of methylene blue on activated carbon from pea shells were studied. The uptake of $\mathrm{MB}$ on activated carbon was examined as a function of temperature, initial dye concentration, adsorbent concentration, contact time, and surfactant. Adsorption isotherms and kinetic parameters were calculated and discussed. The thermodynamics of the adsorption were also evaluated.

\section{Materials and Methods}

2.1. Chemicals and Reagents. MB (basic blue 9, C.I. 52015; chemical formula, $\mathrm{C}_{16} \mathrm{H}_{18} \mathrm{~N}_{3} \mathrm{ClS}$, and molecular weight $319.85 \mathrm{~g} \mathrm{~mol}^{-1}$ ) supplied by Merck was used as an adsorbate and was not purified prior to use. A stock solution of $\mathrm{MB}$ dye was prepared $1000 \mathrm{mg} \mathrm{L}^{-1}$ by dissolving the required amount of dye powder in double distilled water. All working solutions of the desired concentrations were prepared by diluting the stock solution with distilled water. Zinc chloride $\left(\mathrm{ZnCl}_{2}\right)$ and the anionic surfactant sodium dodecylsulfate (SDS) were obtained from Merck. The cationic surfactant cetyltrimethylammonium bromide (CTAB) and the nonionic surfactant polyoxyetheylene (10) cetyl ether (Brij-56) were obtained from Fluka. All the chemicals used were obtained as research-grade chemicals and were used without further purification.

2.2. Preparation of Activated Carbon. Pea shells were collected from local markets in Trakya region, Turkey. Pea shells were repeatedly washed with distilled water to remove dirt, dust, and other impurities. The washed shell materials were then dried in sunlight for two weeks. Chemical activation of the pea shells was carried out with $\mathrm{ZnCl}_{2}$ solution. $10 \mathrm{~g}$ of dried pea shells were well mixed, by stirring, with $100 \mathrm{~mL}$ of an aqueous solution that contained $20 \mathrm{~g}$ of $\mathrm{ZnCl}_{2}$. The mixture was heated at $80^{\circ} \mathrm{C}$ for $1 \mathrm{~h}$. After heating, the slurry was kept in an oven at $100^{\circ} \mathrm{C}$ for $24 \mathrm{~h}$. The resulting $\mathrm{ZnCl}_{2}$ treated sample was then subjected to carbonization and activation process in a programmable electrical furnace (Severn Furnaces Ltd.) at $500^{\circ} \mathrm{C}$ for $1 \mathrm{~h}$. After activation, sample was allowed to cool and subsequently washed with $0.5 \mathrm{M} \mathrm{HCl}$ and then with deionized water several times. It was grounded and sieved through a 65-mesh. The resulting product was kept in a desiccator for further use.

2.3. Adsorption Experiments. Adsorption equilibrium and kinetics were determined by the batch method. Adsorption isotherms were performed in a series of $250 \mathrm{~mL}$ conical flasks where dye solutions $(100 \mathrm{~mL})$ with different initial concentrations (100-350 $\left.\mathrm{mg} \mathrm{L}^{-1}\right)$ at $\mathrm{pH} 6.5$. Equal masses of $0.1 \mathrm{~g}$ of activated carbon were added to dye solutions. The flasks were placed in a thermostated water-bath shaker (Nuve ST 402) and agitation was provided at $150 \mathrm{rpm}$ at different temperatures $\left(25,35,45\right.$, and $\left.55^{\circ} \mathrm{C}\right)$ for $200 \mathrm{~min}$ to ensure establishment of equilibrium. Activated carbon was separated by centrifugation at $3500 \mathrm{rpm}$ (Hettich Rotofix 32A) for $10 \mathrm{~min}$. Residual concentration of $\mathrm{MB}$ was determined spectrophotometrically (Rayleigh UV-1601) at $668 \mathrm{~nm}$. Dilutions were made when absorbance exceeded 1.5. The percentage removal of dye from solution was calculated by the following:

$$
\% \text { Removal }=\frac{\left(C_{o}-C_{t}\right)}{C_{o}} \times 100,
$$

where $C_{0}$ and $C_{t}\left(\mathrm{mg} \mathrm{L}^{-1}\right)$ are the initial dye concentration and concentration at time $t$, respectively.

The procedures of kinetic experiments were basically identical to those of equilibrium tests. The aqueous samples were taken at present time intervals, and the concentrations of dye were similarly measured. All the kinetic experiments were carried out for different dye concentrations (100-350 $\mathrm{mg} \mathrm{L}^{-1}$ ) at $25^{\circ} \mathrm{C}$. The amount of adsorption at time $t, q_{t}\left(\mathrm{mg} \mathrm{g}^{-1}\right)$ was calculated by

$$
q_{t}=\frac{\left(C_{o}-C_{t}\right) V}{W}
$$

\section{Results and Discussion}

3.1. Effect of Contact Time and Initial Concentration of Dye. The adsorption data for the removal of MB versus contact time at different concentrations are presented in Figure 1. The dye removal percentage increased with the increase in contact time and remained constant after an equilibrium time was reached. As shown in Figure 1, as the initial MB concentration increased from 100 to $350 \mathrm{mg} \mathrm{L}^{-1}$ the equilibrium percentage dye removal decreased from 99.65 to $70.71 \%$. This may be attributed to the fact that at low concentrations the ratio of surface active sites to the total dye molecules in the solution is high and hence all dye molecules may interact with the activated carbon. The dynamic equilibrium was influenced by the initial concentration. The time taken to reach equilibrium was 40 and 100 minutes at lower concentrations of 100 and $150 \mathrm{mg} \mathrm{L}^{-1}$, respectively, and 180 minutes for higher concentrations $\left(200,250,300\right.$, and $\left.350 \mathrm{mg} \mathrm{L}^{-1}\right)$.

3.2. Effect of Adsorbent Concentration. The adsorption of methylene blue was investigated by taking the following values as constant: $250 \mathrm{mg} \mathrm{L}^{-1}$ dye concentration, 6.85 value of $\mathrm{pH}, 180$ minutes contact time, a temperature of $25^{\circ} \mathrm{C}$, a stirring speed of $150 \mathrm{rpm}$, and different adsorbent concen-

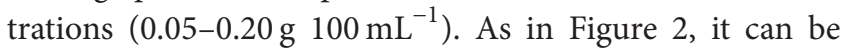
clearly seen that with increasing adsorbent concentration, removal dye percentage also increases. As the adsorbent concentration increases from $0.05 \mathrm{~g}$ to $0.20 \mathrm{~g}$, the removal dye percentage increases from $33.58 \%$ to $99.41 \%$. This is the result of increased surface area and active centers with increasing adsorbent concentration. As it can be seen in Figure 2, when the adsorbent concentration is $0.15 \mathrm{~g}$ and above, the change in suspended dye percentage is very low and the value reaches its maximum.

3.3. Effect of Solution $p H$. The effect of the initial $\mathrm{pH}$ value of the solution on the adsorption process was investigated in conditions of $250 \mathrm{mg} \mathrm{L}^{-1}$ of initial dye solution concen-

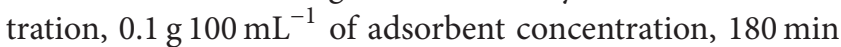




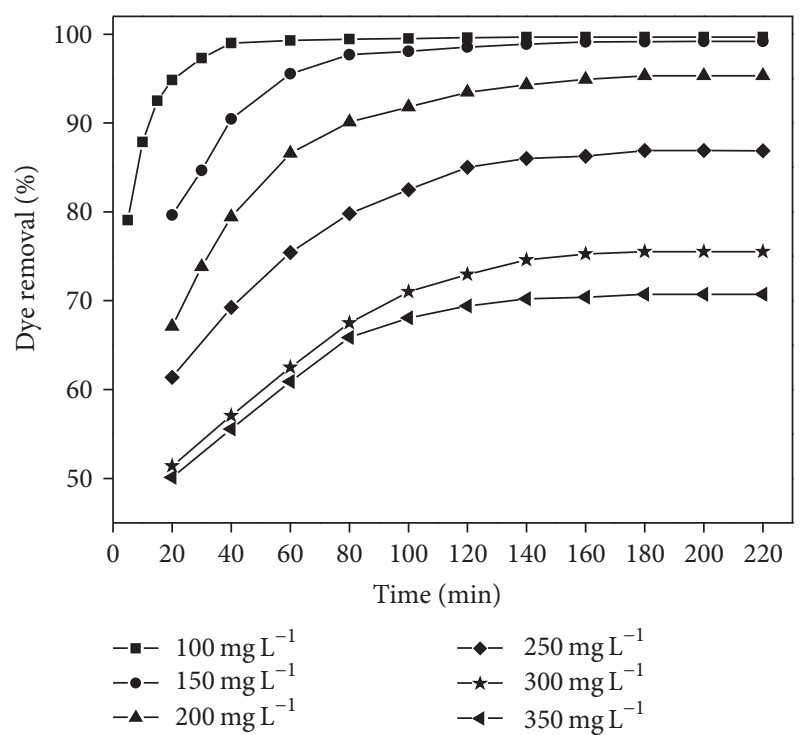

FIGURE 1: Effect of contact time and initial dye concentration on MB adsorption (concentration of adsorbent $=1 \mathrm{~g} \mathrm{~L}^{-1}$, temp. $=25^{\circ} \mathrm{C}$, and $\mathrm{pH}=6.85)$.

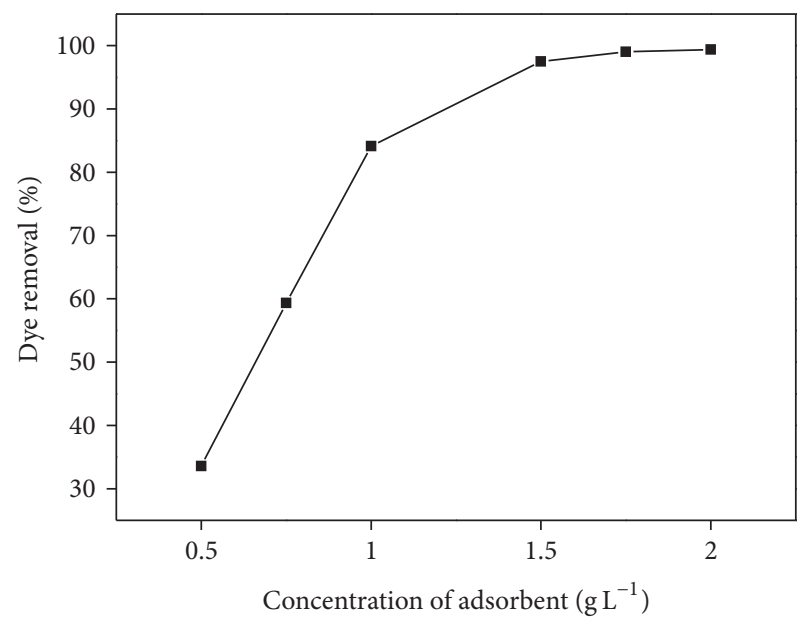

FIGURE 2: Effect of adsorbent concentration on MB adsorption $\left(C_{0}\right.$ $=250 \mathrm{mg} \mathrm{L}^{-1}, \mathrm{pH}=6.85$, temp. $=25^{\circ} \mathrm{C}$, and contact time $\left.=180 \mathrm{~min}\right)$.

of contact time, a temperature of $25^{\circ} \mathrm{C}$, and a $150 \mathrm{rpm}$ stirring speed. The $\mathrm{pH}$ of the dye solution varied between 2.0 and 11.5, as it can be seen in Figure 3. The $\mathrm{pH}_{\mathrm{zpc}}(\mathrm{pH}$ of zero net proton charge) is defined here as the $\mathrm{pH}$ value at which the net surface charge is equal to zero. The point of zero charge $\left(\mathrm{pH}_{\mathrm{zpc}}\right)$ of active carbon that was prepared from pea shells was found to be 5.86. At high $\mathrm{pH}$ values $\left(\mathrm{pH}>\mathrm{pH}_{\mathrm{zpc}}\right)$, the surface of the adsorbent is charged negatively and the adsorption of dye molecules increases due to the electrostatic attraction between the surface and cationic dye molecules. At low $\mathrm{pH}$ values $\left(\mathrm{pH}<\mathrm{pH}_{\mathrm{zpc}}\right.$ ), since the surface of the adsorbent is charged positively, the expected tendency is decreasing adsorption of dye due to the

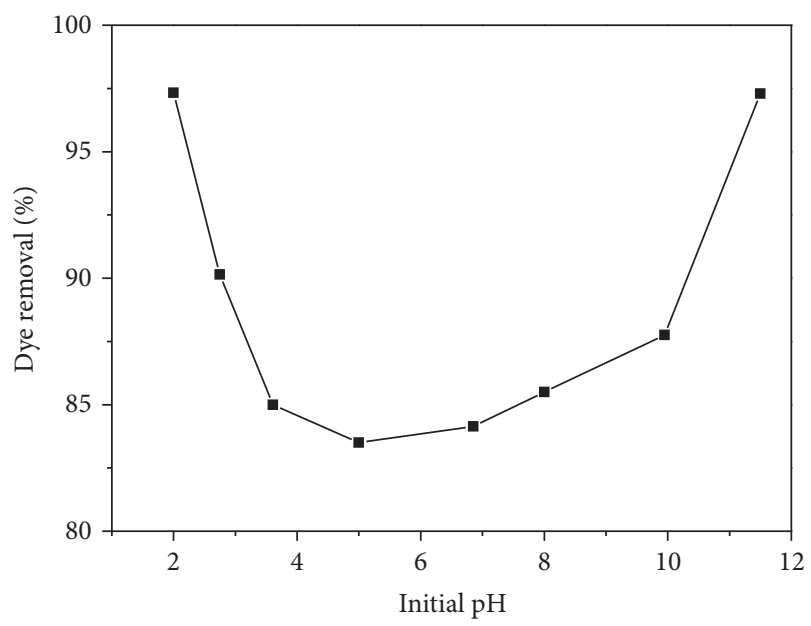

FIgUre 3: Effect of $\mathrm{pH}$ on $\mathrm{MB}$ adsorption $\left(C_{o}=250 \mathrm{mg} \mathrm{L}^{-1}\right.$, concentration of adsorbent $=1 \mathrm{~g} \mathrm{~L}^{-1}$, temp. $=25^{\circ} \mathrm{C}$, and contact time $=180 \mathrm{~min}$ ).

electrostatic repulsive between cationic dye molecules and the surface of the adsorbent. However, in this study, as can be seen in Figure 3, an increase in the percentage of removal dye was observed by both increasing and decreasing $\mathrm{pH}$. At $\mathrm{pH}$ values of 2.0 and 11.5, the maximum percentage of dye removal was found to be $97.30 \%$. At high $\mathrm{pH}$ values, the increase of the dye adsorption can be explained as the negative charging of the surface depending on the $\mathrm{pH}_{\mathrm{zpc}}$ value of the adsorbent. However, at low $\mathrm{pH}$ values, the reason for the dye adsorption value not decreasing can be explained as the replacement of the hydrogen ions on the surface of the adsorbent with the cationic dye molecules in the solution. The fact that, in an acidic medium the initial $\mathrm{pH}$ value of adsorption firstly increases and then reaches an initial value by decreasing can be accepted as an indication of the previous situation.

3.4. Effect of Temperature. The effect of temperature on the adsorption of methylene blue at $0.1 \mathrm{~g}$ in $100 \mathrm{~mL}$ adsorbent concentration, $180 \mathrm{~min}$ of contact time, $\mathrm{pH} 6.85$, and a $150 \mathrm{rpm}$ stirring speed for the different dye concentrations $\left(100-350 \mathrm{~g} \mathrm{~L}^{-1}\right)$ seen in Figure 4 was investigated. As the temperature increased from $25^{\circ} \mathrm{C}$ to $55^{\circ} \mathrm{C}$, the removal of dye percentage also increased. The adsorption capacity increases with temperature due to the increase of the rate of diffusion of the adsorbate molecules across the external boundary layer and the internal pores of the adsorbent particle, which decreases in case viscosity of the solution for highly concentrated suspensions. In addition, changing the temperature will change the equilibrium capacity of the adsorbent for a particular adsorbate $[38,39]$. The maximum removal dye percentage at $55^{\circ} \mathrm{C}$ is found to be $99.85,99.71,98.32,91.89$, 84.84 , and $76.91 \%$ for the dye concentrations of $100,150,200$, 250,300 , and $350 \mathrm{mg} \mathrm{L}^{-1}$, respectively.

3.5. Effect of Surfactants. As surfactants are typically present in wastewater, an effect of their presence on dye adsorption 


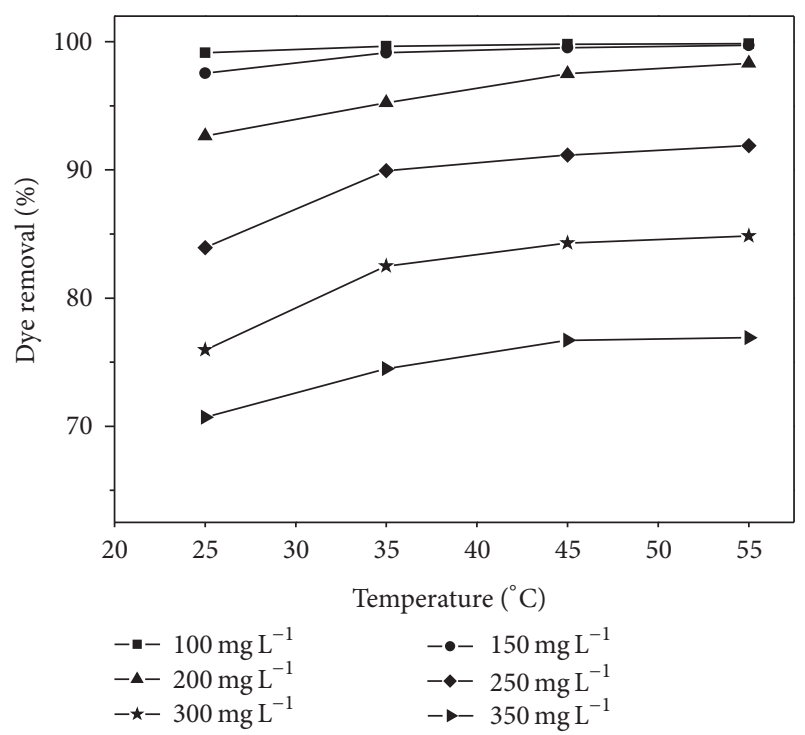

FIGURE 4: Effect of temperature on MB adsorption (concentration of adsorbent $=1 \mathrm{~g} \mathrm{~L}^{-1}, \mathrm{pH}=6.85$, and contact time $=180 \mathrm{~min}$ ).

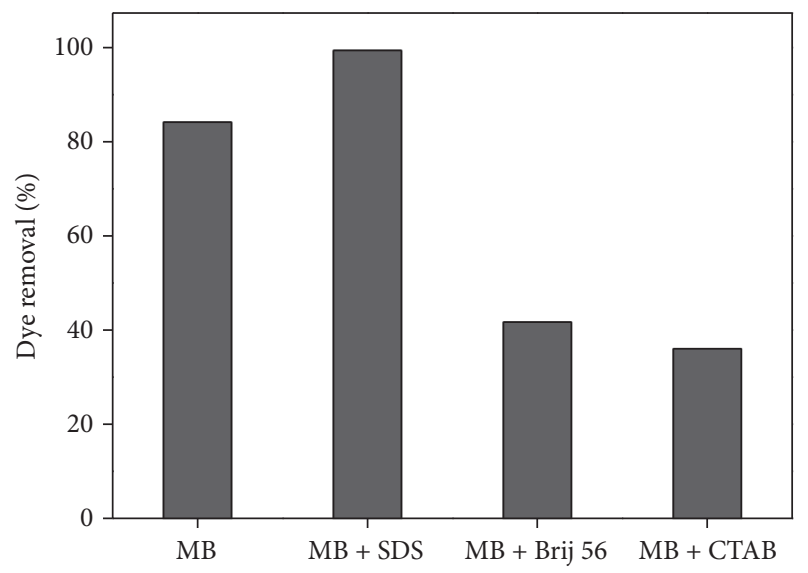

FIGURE 5: Effect of surfactants on $\mathrm{MB}$ adsorption $\left(C_{0}=250 \mathrm{mg} \mathrm{L}^{-1}\right.$, concentration of adsorbent $=1 \mathrm{~g} \mathrm{~L}^{-1}, \mathrm{pH}=6.85$, temp. $=25^{\circ} \mathrm{C}$, and contact time $=180 \mathrm{~min}$ ).

was studied. The effect of surfactants on MB adsorption is shown in Figure 5. From Figure 5, it is clearly seen that the percentage of dye removal in the absence of surfactant is $84.14 \%$ and the percentage of $\mathrm{MB}$ removal in the presence of anionic surfactant SDS increased to $99.38 \%$, on the other hand cationic surfactant $\mathrm{CTAB}$ and nonionic surfactant Brij 56 decreased to $36 \%$ and $41.65 \%$, respectively. This may be explained by the help of the electrostatic attraction (MB-SDS) and repulsion (MB-CTAB) and hydrophobic interactions (MB-Brij 56) between dye and surfactant molecules.

3.6. Adsorption Isotherms. The adsorption isotherm indicates how the adsorption molecules are distributed between the liquid phase and the solid phase when the adsorption process reaches an equilibrium state. An adsorption isotherm study was carried out on two well-known isotherms (Langmuir and Freundlich) at different temperatures. The Langmuir model assumes that the adsorptions occur at specific homogeneous sites on the adsorbent and is used successfully in many monolayer adsorption processes [40]. The Freundlich model endorses the heterogeneity of the surface and assumes that the adsorption occurs at sites with different energy levels of adsorption [41]. The applicability of the isotherm equation is compared by judging the correlation coefficients, $R^{2}$.

The linear form of Langmuir isotherm equation is given as

$$
\frac{C_{e}}{q_{e}}=\frac{1}{Q_{o} b}+\frac{C_{e}}{Q_{o}},
$$

where $C_{e}$ is the equilibrium concentration of the dye solution $\left(\mathrm{mg} \mathrm{L}^{-1}\right), q_{e}$ is the amount of dye adsorbed per unit mass of adsorbent $\left(\mathrm{mgg}^{-1}\right)$, and $Q_{o}\left(\mathrm{mgg}^{-1}\right)$ and $b\left(\mathrm{~L} \mathrm{mg}^{-1}\right)$ are the Langmuir constants related to the maximum adsorption capacity and the rate of adsorption, respectively. As seen in Figure 6 the plots of $C_{e} / q_{e}$ versus $C_{e}$ for the adsorption of $\mathrm{MB}$ onto activated carbon at different temperatures give a straight line of slope $\left(1 / Q_{o}\right)$ and intercept $\left(1 / Q_{o} b\right)$.

The essential characteristics of Langmuir isotherm can be expressed in terms of dimensionless equilibrium parameter $\left(R_{L}\right)$ [42]. The parameter is defined by

$$
R_{L}=\frac{1}{1+b C_{o}},
$$

where $b$ is the Langmuir constant and $C_{o}$ is the highest dye concentration $\left(\mathrm{mg} \mathrm{L}^{-1}\right)$. The value of $R_{L}$ indicates the type of the isotherm to be either unfavorable $\left(R_{L}>1\right)$, linear $\left(R_{L}=\right.$ $1)$, favorable $\left(0<R_{L}<1\right)$, or irreversible $\left(R_{L}=0\right)$.

The logarithmic form Freundlich equation is given by the following:

$$
\ln q_{e}=\ln K_{F}+\frac{1}{n} \ln C_{e},
$$

where $K_{F}\left(\mathrm{mgg}^{-1}\right)\left(\mathrm{L} \mathrm{mg}^{-1}\right)^{1 / n}$ and $1 / n$ are Freundlich constants related to adsorption capacity and adsorption intensity of the adsorbent, respectively. Their values were obtained from the intercepts $\left(\ln K_{F}\right)$ and slope $(1 / n)$ of linear plots of $\ln q_{e}$ versus $\ln C_{e}$ at different temperatures (Figure 7). The slope $1 / n$ ranging between 0 and 1 is a measure of adsorption intensity or surface heterogeneity, becoming more heterogeneous as its value gets closer to zero [43]. A value of $1 / n$ below one indicates a normal Langmuir isotherm while $1 / n$ above one is indicative of cooperative adsorption [44].

Table 1 shows the values of the parameters of the two isotherms and related correlation coefficients at different temperatures. The comparison of correlation coefficients $\left(R^{2}\right)$ of the linearized form of both equations indicates that the Langmuir model yields a better fit for the experimental equilibrium adsorption data than the Freundlich model. With the maximum adsorption capacity, $Q_{o}$ values increased with increasing temperature. Its maximum value was determined 
TABLE 1: The related parameters for the adsorption of MB on activated carbon prepared from pea shell at different temperatures.

\begin{tabular}{lccr}
\hline Adsorption isotherms and its constants & \multicolumn{2}{c}{ Temperatures $\left({ }^{\circ} \mathrm{C}\right)$} & 55 \\
\hline Langmuir adsorption isotherms constants & 25 & 35 & 269.54 \\
$\quad Q_{o}\left(\mathrm{mg} \mathrm{g}^{-1}\right)$ & & & 0.5908 \\
$\quad b\left(\mathrm{~L} \mathrm{mg}^{-1}\right)$ & 246.91 & 0.4576 & 0.9988 \\
$R^{2}$ & 0.2978 & 0.9992 & 0.0048 \\
$R_{L}$ & 0.9973 & 0.0062 & 0.7361 \\
Freundlich adsorption isotherms constants & 0.0095 & & 0.9990 \\
$K_{F}\left(\mathrm{mg} \mathrm{g}^{-1}\right)\left(\mathrm{L} \mathrm{mg}^{-1}\right)^{1 / n}$ & & 129.45 & 0.152 .72 \\
$1 / n$ & 119.32 & 0.1635 & 0.039 \\
$R^{2}$ & 0.1572 & 0.9847 & 0.1423 \\
\end{tabular}

TABLE 2: Comparison of adsorption capacities of various adsorbents for MB.

\begin{tabular}{lcc}
\hline Activated carbon source & $Q_{o}\left(\mathrm{mg} \mathrm{g}^{-1}\right)$ & Reference \\
\hline Pea shell & 246.91 & This work \\
Walnut shells & 3.53 & 33 \\
Pistachio shells & 129.0 & 20 \\
Coir pith & 5.8 & 24 \\
Apricot stones & 4.1 & 33 \\
Almond shell & 1.3 & 33 \\
Hazelnut shell & 8.82 & 33 \\
Euphorbia rigida & 114.45 & 45 \\
Date pits & 80.31 & 22 \\
Mango seed kernel powder & 142.86 & 25 \\
Jute fiber & 225.64 & 19 \\
Coconut tree sawdust & 4.70 & 17 \\
Silk cotton hull & 2.40 & 17 \\
Sago waste & 4.51 & 17 \\
Maize cob & 5.00 & 17 \\
Banana pith & 4.67 & 17 \\
Date pits & 123.10 & 22 \\
Palm fibre & 277.78 & 31 \\
Bamboo dust & 143.20 & 34 \\
Coconut shell & 277.90 & 34 \\
Groundnut shell & 164.90 & 34 \\
Coconut coir dust & 15.25 & 30 \\
Rattan sawdust & 294.12 & 18 \\
\hline
\end{tabular}

as $270 \mathrm{mg} \mathrm{g}^{-1}$ at $55^{\circ} \mathrm{C}$. In the present study, the values of $R_{L}$ were in the range of $0-1$. This again confirmed that the Langmuir isotherm was favorable for adsorption of $\mathrm{MB}$ on the activated carbon prepared from pea shells. Furthermore, from Table 1 it is apparent that the value of the Freundlich constant $1 / n$, obtained for the present systems indicates favorable adsorption, as it lies between 0 and 1 .

Table 2 lists the comparison of the maximum monolayer adsorption capacity of $\mathrm{MB}$ on various adsorbents. Compared with some data in the literature, Table 2 shows that the activated carbon studied in this work has a very large adsorption capacity.

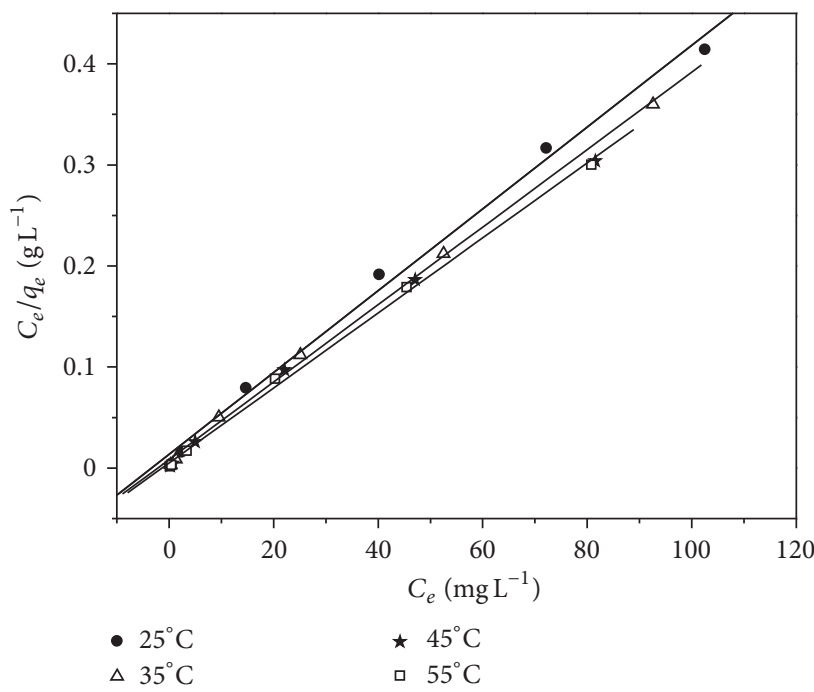

FIGURE 6: Langmuir isotherm plots for MB adsorption at different temperatures.

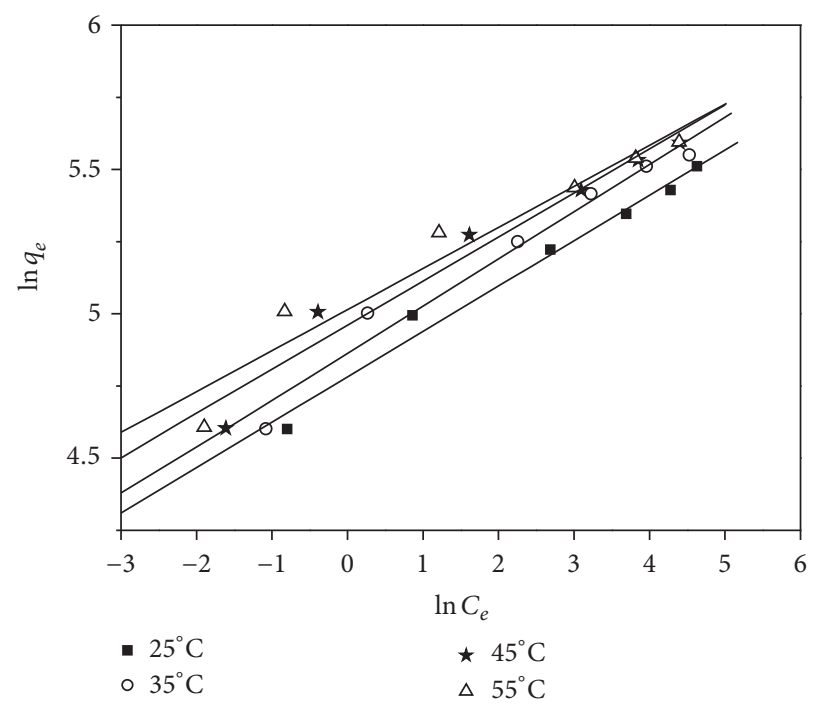

FIGURE 7: Freundlich isotherm plots for MB adsorption at different temperatures. 
TABLE 3: Pseudo-first-order and pseudo-second-order models for the adsorption on activated carbon prepared from pea shell.

\begin{tabular}{|c|c|c|c|c|c|c|}
\hline \multirow[t]{2}{*}{ Kinetic models and its parameters } & \multicolumn{6}{|c|}{ Initial concentrations $(\mathrm{mg} / \mathrm{L})$} \\
\hline & 100 & 150 & 200 & 250 & 300 & 350 \\
\hline$q_{e, \exp }\left(\mathrm{mg} \mathrm{g}^{-1}\right)$ & 99.65 & 148.73 & 190.66 & 217.20 & 227.85 & 247.49 \\
\hline \multicolumn{7}{|l|}{ Pseudo-first-order kinetic } \\
\hline$q_{e, \mathrm{cal}}\left(\mathrm{mg} \mathrm{g}^{-1}\right)$ & 13.36 & 84.49 & 84.86 & 125.96 & 123.08 & 116.17 \\
\hline$k_{1}\left(\min ^{-1}\right)$ & 0.049 & 0.043 & 0.024 & 0.025 & 0.022 & 0.022 \\
\hline$R^{2}$ & 0.9638 & 0.9704 & 0.9958 & 0.9871 & 0.9889 & 0.9830 \\
\hline \multicolumn{7}{|l|}{ Pseudo-second-order kinetic } \\
\hline$q_{e, \mathrm{cal}}\left(\mathrm{mg} \mathrm{g}^{-1}\right)$ & 100.40 & 154.32 & 201.21 & 232.02 & 245.10 & 264.55 \\
\hline$k_{2}\left(\mathrm{~g} \mathrm{mg}^{-1} \min ^{-1}\right)$ & 0.00910 & 0.00110 & 0.00050 & 0.00030 & 0.00028 & 0.00029 \\
\hline$h\left(\mathrm{mgg}^{-1} \min ^{-1}\right)$ & 91.41 & 26.92 & 19.30 & 18.17 & 16.79 & 20.68 \\
\hline$R^{2}$ & 0.9999 & 0.9998 & 0.9999 & 0.9998 & 0.9995 & 0.9993 \\
\hline
\end{tabular}

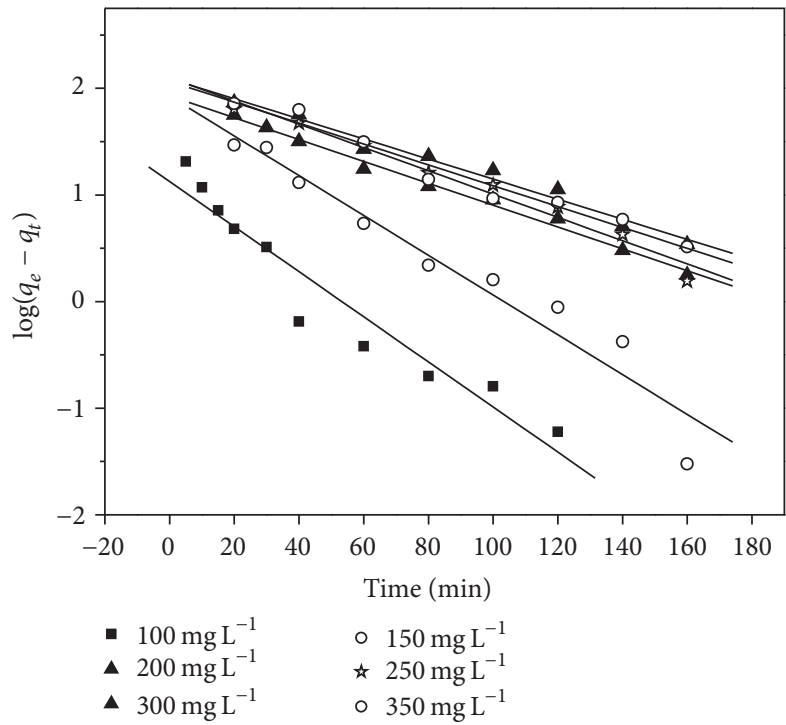

Figure 8: Pseudo-first-order adsorption kinetics of MB.

3.7. Adsorption Kinetics. The kinetic adsorption data were processed to understand the dynamics of adsorption process in terms of the rate constant order. Thus, the kinetic of $\mathrm{MB}$ adsorption onto activated carbon prepared from pea shells was analyzed using pseudo-first-order and pseudo-secondorder kinetic models.

The rate constant of adsorption is determined from the pseudo-first-order equation given by Langergren and Svenska [45]:

$$
\log \left(q_{e}-q_{t}\right)=\log q_{e}-\frac{k_{1}}{2.303} t
$$

where $q_{e}$ and $q_{t}$ are the amounts of $\mathrm{MB}$ adsorbed $\left(\mathrm{mg} \mathrm{g}^{-1}\right)$ at equilibrium and at time $t(\mathrm{~min})$, respectively, and $k_{1}\left(\mathrm{~min}^{-1}\right)$ is the adsorption rate constant. A plot of $\log \left(q_{e}-q_{t}\right)$ versus $t$ should give a linear relationship, from which $k_{1}$ and $q_{e}$ can be determined from the slope and intercept of the plot, respectively (Figure 8).

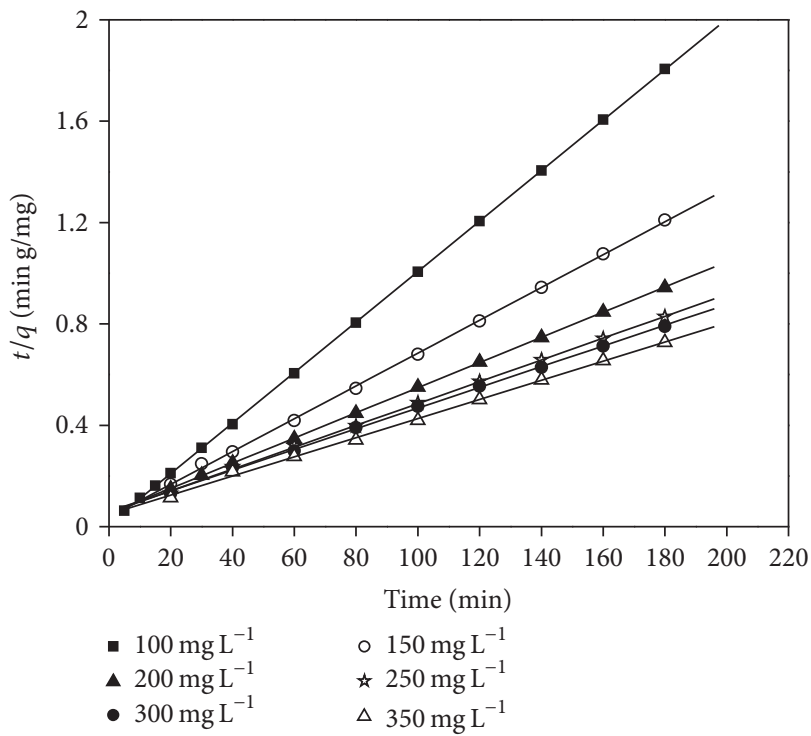

FIgURE 9: Pseudo-second-order adsorption kinetics of MB.

The pseudo-second-order kinetic model [46] is expressed as

$$
\begin{gathered}
\frac{t}{q_{t}}=\frac{1}{k_{2} q_{e}^{2}}+\frac{1}{q_{e}} t, \\
h=k_{2} q_{e}^{2},
\end{gathered}
$$

where $h$ is the initial adsorption rate $\left(\mathrm{mgg}^{-1} \min ^{-1}\right)$ and $k_{2}$ $\left(\mathrm{g} \mathrm{mg}^{-1} \mathrm{~min}^{-1}\right)$ is rate constant of second-order adsorption. If the second-order kinetics is applicable, then the plot of $t / q_{t}$ versus $t$ should show a linear relationship. Values of $k_{2}$ and equilibrium adsorption capacity $q_{e}$ were calculated from the intercept and slope of the plots $t / q_{t}$ versus $t$ (Figure 9).

Table 3 lists the results of the rate constant studies for different initial dye concentrations by the pseudo-first-order and second-order models. The correlation coefficient, $R^{2}$ for the pseudo-second-order adsorption model has a high value, and its calculated equilibrium adsorption capacity, $q_{e, \text { cal }}$, is consistent with experimental data, $q_{e, \text { exp }}$. Hence it can be 
TABLE 4: Values of thermodynamics parameters for MB adsorption on activated carbon prepared from pea shell.

\begin{tabular}{|c|c|c|c|c|}
\hline Temperature $(\mathrm{K})$ & $\Delta G^{\circ}\left(\mathrm{kJ} \mathrm{mol}^{-1}\right)$ & $\Delta H^{\circ}\left(\mathrm{kJ} \mathrm{mol}^{-1}\right)$ & $\Delta S^{\circ}\left(\mathrm{kJ} \mathrm{mol}^{-1} \mathrm{~K}^{-1}\right)$ & $R^{2}$ \\
\hline 298 & -28.40 & 14.57 & 0.147 & 0.9891 \\
\hline 308 & -30.46 & & & \\
\hline 318 & -32.12 & & & \\
\hline 328 & -33.73 & & & \\
\hline
\end{tabular}

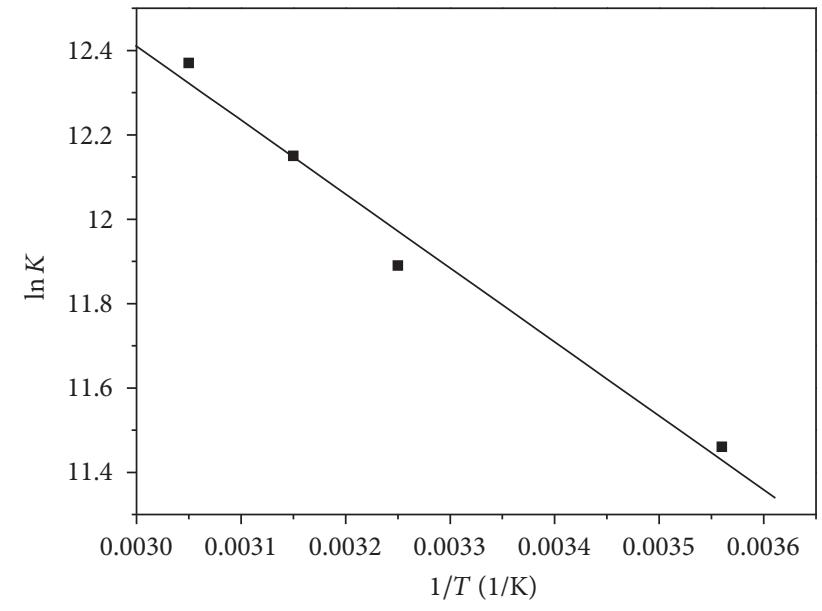

FIgURE 10: Plot of $\ln K$ versus $1 / T$ for the enthalpy change of the adsorption process.

assumed that the adsorption of MB follows the pseudosecond-order kinetic model.

3.8. Thermodynamic Studies. Thermodynamic parameters including Gibbs free energy change $\left(\Delta G^{\circ}\right)$, enthalpy change $\left(\Delta H^{\circ}\right)$, and entropy change $\left(\Delta S^{\circ}\right)$ were calculated from the following:

$$
\begin{gathered}
\Delta G^{\circ}=-R T \ln K, \\
\ln K=\frac{\Delta S^{o}}{R}-\frac{\Delta H^{o}}{R T},
\end{gathered}
$$

where $R$ is the universal gas constant $\left(8.314 \mathrm{~J} \mathrm{~mol}^{-1} \mathrm{~K}^{-1}\right), T$ is the absolute temperature (Kelvin), and $K$ is the equilibrium constant. Since Langmuir adsorption isotherm is the best fit, the value of $b$ was used in place of $K$ in the calculations of all thermodynamic parameters.

Equation (11) is known as the van't Hoff equation, and it expresses a relationship between equilibrium constant and temperature. Plots of $\ln K$ versus $1 / T$ should be a straight line as shown in Figure 10. The values of $\Delta H^{\circ}$ and $\Delta S^{\circ}$ were calculated from the slope and intercept of van't Hoff plote, respectively. The thermodynamic parameters associated with the adsorption of $\mathrm{MB}$ onto activated carbon prepared from pea shells are listed in Table 4. Negative values of $\Delta G^{\circ}$ show the feasibility and spontaneity of the adsorption process. According to the van't Hoff equation, standard enthalpy and the entropy values in the range of $25-55^{\circ} \mathrm{C}$ were obtained as $14.57 \mathrm{k} \mathrm{J} \mathrm{mol}^{-1}$ and $0.147 \mathrm{k} \mathrm{mol}^{-1} \mathrm{~K}^{-1}$, respectively. The positive value of $\Delta H^{\circ}$ indicates the endothermic nature of the adsorption process. From Table 1, the maximum adsorption capacity increased from 246.91 to $270.00 \mathrm{mgg}^{-1}$ with an increase in solution temperature from 25 to $55^{\circ} \mathrm{C}$. This further confirmed the endothermic nature of the adsorption process. The positive value of $\Delta S^{\circ}$ shows the increasing randomness of the solid-solution and adsorption medium interface during the adsorption.

\section{Conclusions}

The adsorption of $\mathrm{MB}$ from aqueous solution onto activated carbon prepared from pea shells has been studied. The removal of methylene blue from wastewater is primarily controlled by the dye concentration in the wastewater, the adsorbent concentration, the $\mathrm{pH}$ of the wastewater, and the temperature of the adsorption process. The percentage of dye removal was found to increase with an increase in solution temperature, contact time, and adsorbent concentration and found to decrease with an increase in initial dye concentration. The percentage of dye removal increased with increases and decreases in $\mathrm{pH}$ and the maximum adsorption was obtained at $\mathrm{pH} 2.0$ and 11.5. It was found that the sorption of the methylene blue was increased by the presence of anionic surfactant, and on the other hand was decreased by the presence of cationic and nonionic surfactant. Equilibrium data were fitted to Langmuir and Freundlich isotherms and the equilibrium data were best described by the Langmuir isotherm model, with maximum adsorption capacity of $246.91 \mathrm{mg} \mathrm{g}^{-1}$ at $25^{\circ} \mathrm{C}$. The kinetics of the adsorption process was found to follow the pseudosecond-order kinetic model. By second-order model to study the mechanism of adsorption, calculated $q_{e}$ value agreed well with the $q_{e}$ experimental values. The thermodynamic parameters indicate that the adsorption process is endothermic and spontaneous in nature. As a result of this study, activated carbon prepared from pea shells can be used as an effective adsorbent for the removal of methylene blue from wastewater.

\section{Acknowledgment}

The authors do not have financial connection with the commercial identities mentioned in this study.

\section{References}

[1] B. Acemioğlu, "Adsorption of congo red from aqueous solution onto calcium-rich fly ash," Journal of Colloid and Interface Science, vol. 274, no. 2, pp. 371-379, 2004. 
[2] V. K. Gupta, A. Mittal, L. Krishnan, and V. Gajbe, "Adsorption kinetics and column operations for the removal and recovery of malachite green from wastewater using bottom ash," Separation and Purification Technology, vol. 40, no. 1, pp. 87-96, 2004.

[3] D. S. Kim and B. Y. Park, "Effects on the removal of Pb2+ from aqueous solution by crab shell," Journal of Chemical Technology and Biotechnology, vol. 76, no. 11, pp. 1179-1184, 2001.

[4] B. Acemioğlu, "Batch kinetic study of sorption of methylene blue by perlite," Chemical Engineering Journal, vol. 106, no. 1, pp. 73-81, 2005.

[5] V. K. Gupta and Suhas, "Application of low-cost adsorbents for dye removal-a review," Journal of Environmental Management, vol. 90, no. 8, pp. 2313-2342, 2009.

[6] V. K. Gupta, A. Mittal, L. Kurup, and J. Mittal, "Adsorption of a hazardous dye, erythrosine, over hen feathers," Journal of Colloid and Interface Science, vol. 304, no. 1, pp. 52-57, 2006.

[7] A. Pala and E. Tokat, "Color removal from cotton textile industry wastewater in an activated sludge system with various additives," Water Research, vol. 36, no. 11, pp. 2920-2925, 2002.

[8] S. V. Mohan and J. Karthikeyan, "Removal of lignin and tannin colour from aqueous solution by adsorption onto activated charcoal," Environmental Pollution, vol. 97, no. 1-2, pp. 183-187, 1997.

[9] V. K. Gupta, S. Srivastava, and D. Mohan, "Equilibrium uptake, sorption dynamics, process optimization, and column operations for the removal and recovery of malachite green from wastewater using activated carbon and activated slag," Industrial \& Engineering Chemistry Research, vol. 36, no. 6, pp. 2207-2218, 1997.

[10] K. Mohanty, J. T. Naidu, B. C. Meikap, and M. N. Biswas, "Removal of crystal violet from wastewater by activated carbons prepared from rice husk," Industrial and Engineering Chemistry Research, vol. 45, no. 14, pp. 5165-5171, 2006.

[11] K. Mohanty, M. Jha, B. C. Meikap, and M. N. Biswas, "Removal of chromium (VI) from dilute aqueous solutions by activated carbon developed from Terminalia arjuna nuts activated with zinc chloride," Chemical Engineering Science, vol. 60, no. 11, pp. 3049-3059, 2005.

[12] V. K. Gupta, A. Mittal, R. Jain, M. Mathur, and S. Sikarwar, "Adsorption of Safranin-T from wastewater using waste materials- activated carbon and activated rice husks," Journal of Colloid and Interface Science, vol. 303, no. 1, pp. 80-86, 2006.

[13] P. Álvarez, C. Blanco, and M. Granda, "The adsorption of chromium (VI) from industrial wastewater by acid and baseactivated lignocellulosic residues," Journal of Hazardous Materials, vol. 144, no. 1-2, pp. 400-405, 2007.

[14] J. Guo and A. C. Lua, "Textural and chemical characterisations of activated carbon prepared from oil-palm stone with $\mathrm{H}_{2} \mathrm{SO}_{4}$ and $\mathrm{KOH}$ impregnation," Microporous and Mesoporous Materials, vol. 32, no. 1-2, pp. 111-117, 2007.

[15] A. P. Carvalho, M. Gomes, A. S. Mestre, J. Pires, and M. B. de Carvalho, "Activated carbons from cork waste by chemical activation with $\mathrm{K}_{2} \mathrm{CO}_{3}$. Application to adsorption of natural gas components," Carbon, vol. 42, no. 3, pp. 672-674, 2004.

[16] J. Hayashi, A. Kazehaya, K. Muroyama, and A. P. Watkinson, "Preparation of activated carbon from lignin by chemical activation," Carbon, vol. 38, no. 13, pp. 1873-1878, 2000.

[17] K. Kadirvelu, M. Kavipriya, C. Karthika, M. Radhika, N. Vennilamani, and S. Pattabhi, "Utilization of various agricultural wastes for activated carbon preparation and application for the removal of dyes and metal ions from aqueous solutions," Bioresource Technology, vol. 87, no. 1, pp. 129-132, 2003.
[18] B. H. Hameed, A. L. Ahmad, and K. N. A. Latiff, "Adsorption of basic dye (methylene blue) onto activated carbon prepared from rattan sawdust," Dyes and Pigments, vol. 75, no. 1, pp. 143-149, 2007.

[19] S. Senthilkumaar, P. R. Varadarajan, K. Porkodi, and C. V. Subbhuraam, "Adsorption of methylene blue onto jute fiber carbon: kinetics and equilibrium studies," Journal of Colloid and Interface Science, vol. 284, no. 1, pp. 78-82, 2005.

[20] A. A. Attia, B. S. Girgis, and S. Khedr, "Capacity of activated carbon derived from pistachio shells by $\mathrm{H}_{3} \mathrm{PO}_{4}$ in the removal of dyes and phenolics," Journal of Chemical Technology and Biotechnology, vol. 78, no. 6, pp. 611-619, 2003.

[21] A. Jumasiah, T. G. Chuah, J. Gimbon, T. S. Y. Choong, and I. Azni, "Adsorption of basic dye onto palm kernel shell activated carbon: sorption equilibrium and kinetics studies," Desalination, vol. 186, no. 1-3, pp. 57-64, 2005.

[22] F. Banat, S. Al-Asheh, and L. Makhadmeh, "Preparation and examination of activated carbons from date pits impregnated with potassium hydroxide for the removal of methylene blue from aqueous solutions," Adsorption Science and Technology, vol. 21, no. 6, pp. 597-606, 2003.

[23] M. Sankar, G. Sekaran, S. Sadulla, and T. Ramasami, "Removal of diazo and triphenylmethane dyes from aqueous solutions through an adsorption process," Journal of Chemical Technology and Biotechnology, vol. 74, no. 4, pp. 337-344, 1999.

[24] D. Kavitha and C. Namasivayam, "Experimental and kinetic studies on methylene blue adsorption by coir pith carbon," Bioresource Technology, vol. 98, no. 1, pp. 14-21, 2007.

[25] K. Vasanth and A. Kumaran, "Removal of methylene blue by mango seed kernel powder," Biochemical Engineering Journal, vol. 27, no. 1, pp. 83-93, 2005.

[26] B. G. P. Kumar, L. R. Miranda, and M. Velan, "Adsorption of bismark brown dye on activated carbons prepared from rubberwood sawdust (Hevea brasiliensis) using different activation methods," Journal of Hazardous Materials, vol. 126, no. 1-3, pp. 63-70, 2005.

[27] R. S. Juang, F. C. Wu, R. L. Tseng, and R. L. J, "Mechanism of adsorption of dyes and phenols from water using activated carbons prepared from plum kernels," Journal of Colloid and Interface Science, vol. 227, no. 2, pp. 437-444, 2000.

[28] V. K. Garg, M. Amita, R. Kumar, and R. Gupta, "Basic dye (methylene blue) removal from simulated wastewater by adsorption using Indian Rosewood sawdust: a timber industry waste," Dyes and Pigments, vol. 63, no. 3, pp. 243-250, 2004.

[29] N. Kannan and M. Meenakshisundaram, "Adsorption of Congo Red on various activated carbons," Water, Air, and Soil Pollution, vol. 138, no. 1-4, pp. 289-305, 2002.

[30] J. S. Macedo, N. B. Júnior, L. E. Almeida et al., "Kinetic and calorimetric study of the adsorption of dyes on mesoporous activated carbon prepared from coconut coir dust," Journal of Colloid and Interface Science, vol. 298, no. 2, pp. 515-522, 2006.

[31] I. A. W. Tan, B. H. Hameed, and W. A. L. Ahmad, "Equilibrium and kinetic studies on basic dye adsorption by oil palm fibre activated carbon," Chemical Engineering Journal, vol. 127, no. 1-3, pp. 111-119, 2007.

[32] Ü Geçgel, K. Sezer, and H. Kolancılar, "Removal of Cu(II) ions from aqueous solutions by the activated carbon obtained from pine cone," Asian Journal of Chemistry, vol. 22, no. 5, pp. 3936-3942, 2010.

[33] A. Aygün, S. Yenisoy-Karakaş, and I. Duman, "Production of granular activated carbon from fruit stones and nutshells 
and evaluation of their physical, chemical and adsorption properties," Microporous and Mesoporous Materials, vol. 66, no. 2-3, pp. 189-195, 2003.

[34] N. Kannan and M. M. Sundaram, "Kinetics and mechanism of removal of methylene blue by adsorption on various carbons-a comparative study," Dyes and Pigments, vol. 51, no. 1, pp. 25-40, 2001.

[35] V. K. Gupta, A. Mittal, V. Gajbe, and J. Mittal, "Adsorption of basic fuchsin using waste materials-bottom ash and deoiled soya-as adsorbents," Journal of Colloid and Interface Science, vol. 319, no. 1, pp. 30-39, 2008.

[36] V. K. Gupta, R. Jain, and S. Varshney, "Removal of Reactofix golden yellow 3 RFN from aqueous solution using wheat huskAn agricultural waste," Journal of Hazardous Materials, vol. 142, no. 1-2, pp. 443-448, 2007.

[37] V. K. Gupta, P. J. M. Carrott, M. M. L. Carrott, and L. Suhas, "Low-Cost adsorbents: growing approach to wastewater treatmenta review," Critical Reviews in Environmental Science and Technology, vol. 39, no. 10, pp. 783-842, 2009.

[38] M. Alkan, M. Doğan, Y. Turhan, O. Demirbaş, and P. Turan, "Adsorption kinetics and mechanism of maxilon blue 5G dye on sepiolite from aqueous solutions," Chemical Engineering Journal, vol. 139, no. 2, pp. 213-223, 2008.

[39] M. M. Abd El-Latif and A. M. Ibrahim, "Adsorption, kinetic and equilibrium studies on removal of basic dye from aqueous solutions using hydrolyzed Oak Sawdust," Desalination and Water Treatment, vol. 6, no. 1-3, pp. 252-268, 2009.

[40] I. Langmuir, "The adsorption of gases on plane surfaces of glass, mica and platinum," The Journal of the American Chemical Society, vol. 40, no. 9, pp. 1361-1403, 1918.

[41] H. Freundlich, "Uber Die Adsorption in Losungen," The Journal of Physical Chemistry, vol. 57, pp. 385-470, 1907.

[42] T. W. Weber and R. K. Chakkravorti, "Pore and solid diffusion models for fixed-bed adsorbers," AIChE Journal, vol. 20, pp. 228-238, 1974.

[43] F. Haghseresht and G. Q. Lu, "Adsorption characteristics of phenolic compounds onto coal-reject-derived adsorbents," Energy and Fuels, vol. 12, no. 6, pp. 1100-1107, 1998.

[44] K. Fytianos, E. Voudrias, and E. Kokkalis, "Sorption-desorption behaviour of 2,4-dichlorophenol by marine sediments," Chemosphere, vol. 40, no. 1, pp. 3-6, 2000.

[45] S. Langergren and B. K. Svenska, "Zur theorie der sogenannten adsorption geloester stoffe," Veternskapsakad Handlingar, vol. 24, no. 4, pp. 1-39, 1898.

[46] Y. S. Ho and G. McKay, "Sorption of dye from aqueous solution by peat," Chemical Engineering Journal, vol. 70, no. 2, pp. 115-124, 1998. 

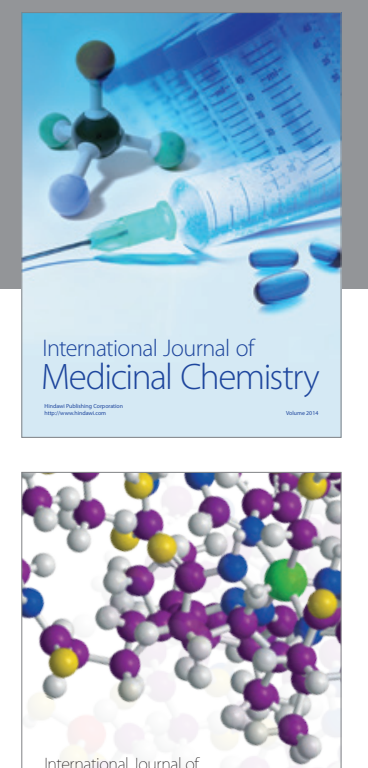

\section{Carbohydrate} Chemistry

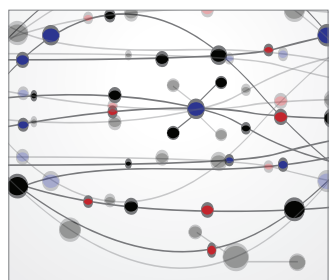

The Scientific World Journal
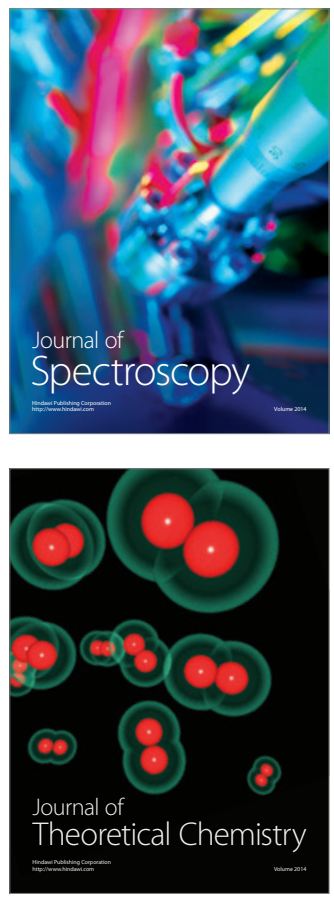
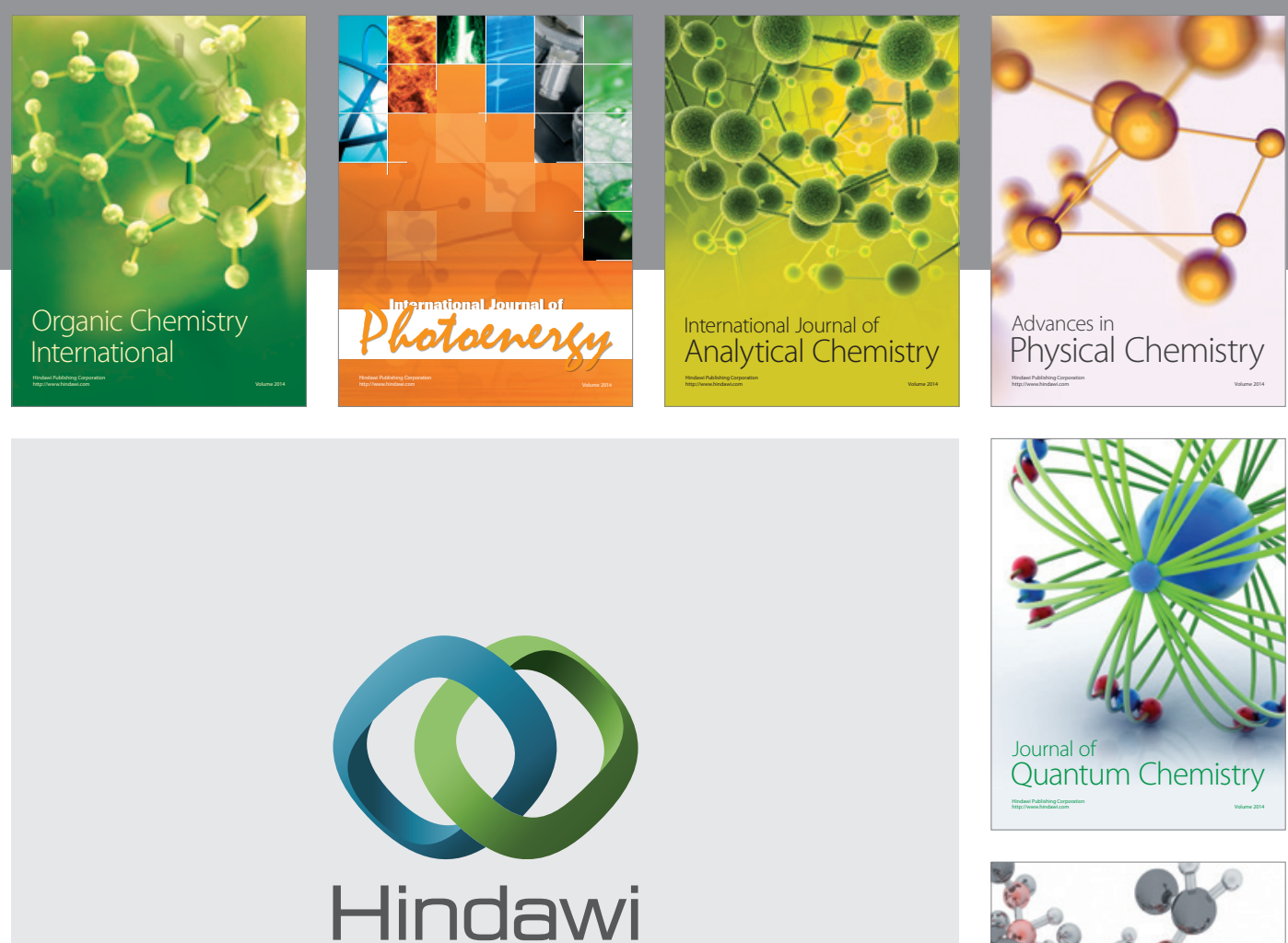

Submit your manuscripts at

http://www.hindawi.com

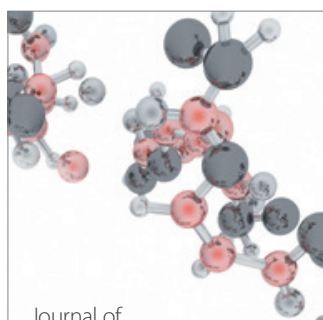

Analytical Methods

in Chemistry

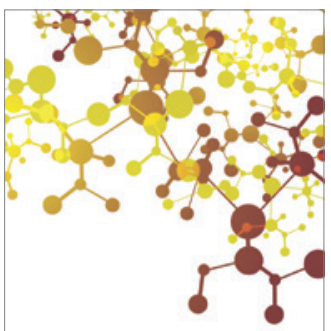

Journal of

Applied Chemistry

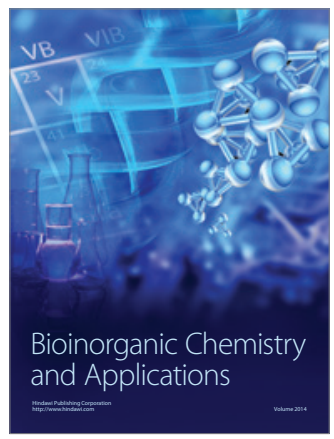

Inorganic Chemistry
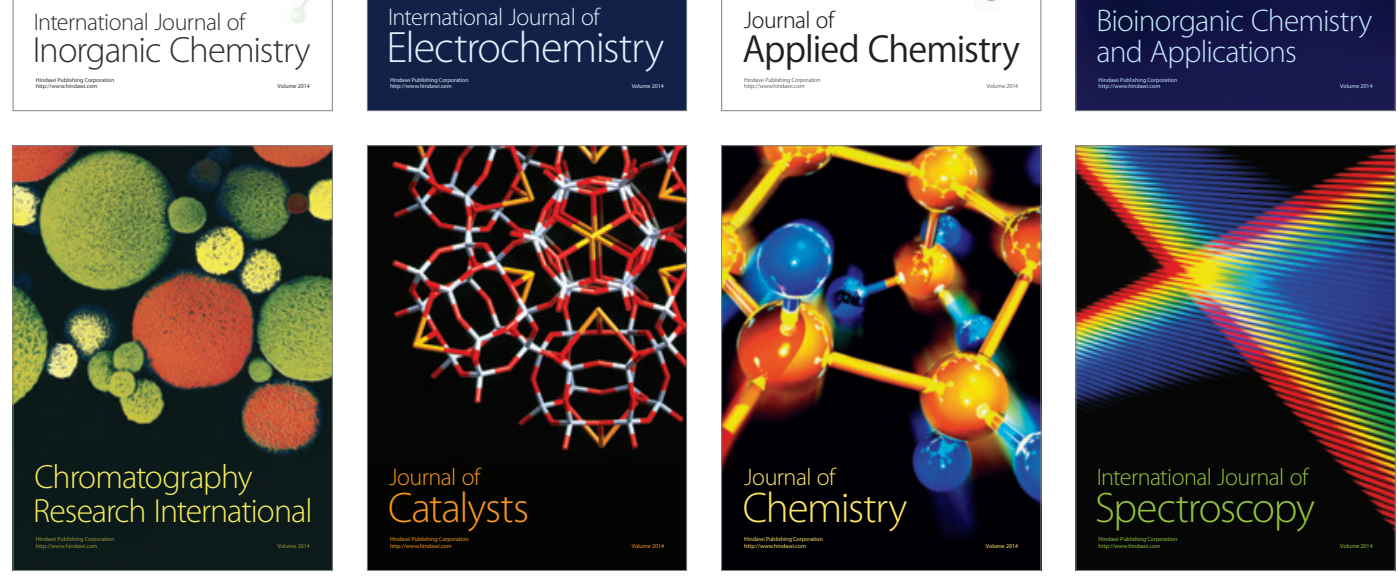